WSRC-TR- $-90-538$

DE92 009428

Whom

likili 101992

\title{
ESTIMATING THE DOSE FROM ATMOSPHERIC RELEASES OF HT (U)
}

CeM

Chiarles E. Murphy Jr.

Westinghouse Savannah River Company

Savannah River Site

Aiken, SC 29808

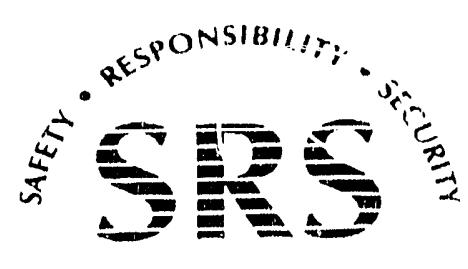

SAVANNAH RIVER SITE

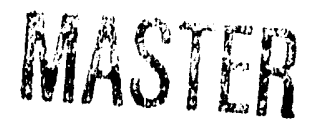

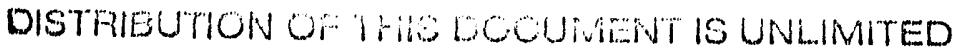




\section{DISCLAIMER}

This report was prepared by Westinghouse Savannah River Company (WSRC) for the United States Department of Energy under Contract No. DE-ACO989 SR $18($ ()35 and is an account of work performed under that contract. Neither the United States Department of Energy, nor WSRC, nor any of their employees makes any warranty, expressed or implied, or assumes any legal liability or responsibility for the accuracy, completeness, or usefulness, of any information, apparatus, or product or process disclosed herein or represents that its use will not infringe privately owned rights. Reference herein to any specific comercial product, process, , or service by trademark, name, manufacturer or otherwise does not necessarily constitute or imply endorsement, recommendation, or favoring of same by WSRC or by the United States Government or any agency thereof. The views and opinions of the authors expressed herein do not necessarily state or reflect those of the United States Government or any agency thereof. 
WSRC-TR.90-538

D.B. Moore, Manager

Authorized Derivative Classifier

ESTIMATING THE DOSE FROM ATMOSPHERIC RELEASES OF HT(U)

Charles E. Murphy Jr.

Publication Date: November 13, 1990

Approved By: D.B. Moore, Manager

Environmental Sciences Section

Savannah River Laboratory

Westinghouse Savannah River Company

Savannah River Site

Aiken, SC 29808

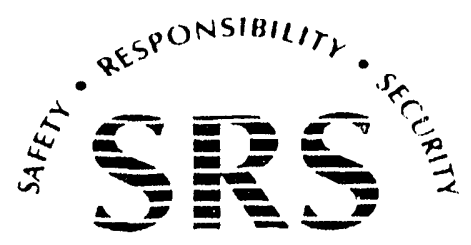

SAVANNAH RIVERSITE

THIS DOCUMENT WAS PREPARED IN CONNECTION WITH WORK UNDER THE U.S. DEPARTMENT OF ENER(;Y (CONTRACT DE-AC09-89SR18035). 
Measurements of uptake of tritium by humans and laboratory animals following exposure to tritiated hydrogen gas, HT, suggest that the radiotoxicity of HT is four orders of magnitude less than that of tritiated water, HTO. However, this analysis does not take in to account the conversion of HT into HTO following release into the environment. Experimental releases of HT have demonstrated that HT release to the environment is converted to HTO by soil microorganisms. ${ }^{\prime}$ In this report two methods are used to estimate the effect of HT to HTO conversion on the inhalation dose of individuals exposed to tritium downwind of a release of HT.

From this analysis it is predicted that the ratio of dose from inhalation of tritium following an atmospheric release of HT, as compared to inhalation of HTO, is closer to 0.01 than to the 0.0001 attributed to simple HT inhalation. Under meteorologic conditions which keep the HT release near the surface and promote optimum soil microbial activity, the analysis suggests that the ratio of dose from an atmospheric HT release could be as high as $5 \%$ of that from an atmospheric HTO release. 
INTRODUCTION

1

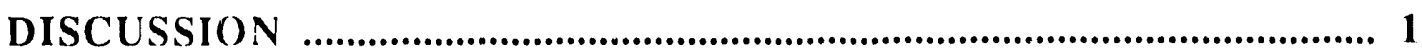

Dose based on Local Re-emission of HTO .................................................... 2

Calculation of IIT Dose Under Worst Conditions ........................................ 6

Estimation of Deposition Velocities from

Atmospheric HT Half Life ........................................................ 10

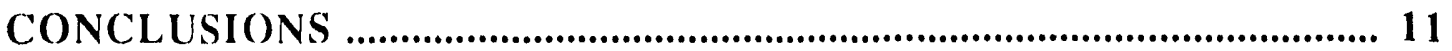

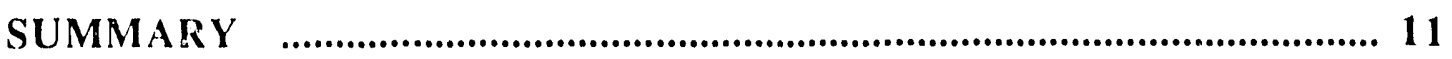

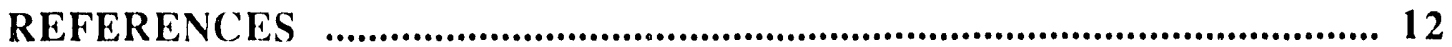


1. The Ratio of Inhalation Dose from Re-emitted HTO to Dose from HT ....... 3

2. Comparison of the Inhalation Dose from an HT Release to the Dose from an HTO Release of the same Size...................... 4

3. Comparison of Dose from Conversion of HT to HTO and HT Inhalation only .................................................................. 8

4. Comparison of the Doses from an HT Release, including HT Oxidation to HTO in Soil, and the Dose from an HTO Release of the same Size.....................................................................

1. Ratio Dose Due to HTO and Dose due to HT 1

2. Results of Calculations of the Dose due to Conversion of

HT to HT() from an Atmospheric Release of HT

3. Calculation of Effect of HT to HTO Conversion by Soil for

Fumigation Conditions at Mixing Depth of 100 Meters,

Deposition Velocity of $0.001 \mathrm{~m} / \mathrm{s}$, Wind Speed of $2 \mathrm{~m} / \mathrm{s}$,

Release Time of 60 Minutes, and a $100 \mathrm{~Bq} / \mathrm{s}$ Release Rate ....... 10

4. The Effect of Mixed Depth and Deposition Velocity on the

Long-Term Removal of Tritium HT from the Atmosphere 


\title{
ESTIMATING THE DOSE FROM ATMOSPHERIC RELEASES OF HT
}

\author{
By C.E. Murphy Jr. \\ Westinghouse Savannah River Company \\ Savannah River Laboratory \\ Aiken, SC 29808
}

\section{INTRODUCTION}

Measurements of uptake of tritium by humans and laboratory animals following exposure to tritiated hydrogen gas, HT, suggest that the radiotoxicity of HT is four orders of magnitude less than that of tritiated water, HTO. However, this analysis does not take into account the conversion of HT into HTO following release into the environment. Experimental release of HT have demonstrated that the majority of dose from an HT release was the result of HTO converted before release or by soil microorganisms in the environment after the release. ${ }^{\prime}$ In this report two methods are used to estimate the effect of HT to HTO conversion on the inhalation dose of individuals exposed totritium downwind of a release of HT. The latter method attempts to calculate an upper bound to the dose from an atmospheric $\mathrm{HT}$ release.

\section{DISCUSSION}

A few measurements have been made which give some indication of the dose due to HT inhalation relative to that due to inhalation of $\mathrm{HTO}$ from conversion in the environment after the release. ${ }^{1,2}$

Table 1. Ratio Dose Due to HTO and Dose due to HT

$\begin{array}{lrrrr}\text { Distance } & \mathbf{8 0 0 m} & 1000 \mathrm{~m} & \mathbf{2 2 0 0 m} & 15000 \mathrm{~m} \\ \begin{array}{l}\text { Source } \\ \text { Watts and Murphy }\end{array} & - & - & - & 5.7 \\ \text { Djerrassi and Lesigne } & 4.8 & 19.3 & 71.8 & -\end{array}$

These results do not provide enough information to determine the expected range of this ratio, nor do they provide a method of calculating the ratio for other conditions. In this discussion a primitive model of the deposition and re-emission processes will be used to get a better understanding of the effect of the environment on the dose due to deposition of HT, the conversion of HT to HTO in the soil, and the remission of HTO into the atmosphere.

The deposition of HT to soils has been measured a number of times in both laboratory and field conditions. The results are reported as a deposition velocity, the deposition rate divided b" the concentration (which has the units of velocity). $3,4,5,6,7,8,9$ The range in values found in field experiments is from less than $0.0001 \mathrm{~m} / \mathrm{s}$ to around $0.001 \mathrm{~m} / \mathrm{s}$. Higher values have been found, for short periods of exposure, in laboratory experiments. ${ }^{6,10}$ Using the deposition velocity $\left(v_{d}\right)$, the average concentration in the atmosphere $\left(\chi_{a}\right)$, and the time of exposure, the deposition per unit of ground surface $(F)$ can be 
calculated.

$$
F=v_{d} \chi_{a} t
$$

Re-emission of HTO, from oxidation of the HT deposited in the soil, depends on meteorological and soil conditions. Field measurements indicate that from 2 to 10 percent of the HTO remaining in the soil after exposure of soil to HT will reenter the atmosphere each hour. ${ }^{2,11,12}$

Most of the HTO is deposited in the surface layer of the soil and finally reenters the atmosphere by diffusion or root uptake and evaporation from vegetation. Only if rainfall (or irrigation) displaces the HTO and moves it below the rooting zone, will it be prevented from reentering the atmosphere. In most cases it is reasonable to assume that all the HTO will reach the atmosphere. If most of the HTO reenters the atmosphere, the exposure to humans breathing the HTO vapor will not depend on the re-emission rate. If the re-emission rate is high the air concentration will be high but the exposure time will be low because the soil will be depleted of HTO. If the re-emission rate is low, the air concentration will be low but the exposure time will be longer. The resulting integrated exposure time will be the same in either case.

\section{Dose Based on Local Re-emission of HTO}

The integrated exposure to the HTO is the product of the average concentration of HTO in the air and the exposure time $\left(t_{\mathrm{c}}\right)$. The concentration at the breathing height (here taken to be 1.5 meters) can be calculated from a known re-emission rate if the processes which mix the re-emitted HTO into the :tmosphere can be predicted.

$$
\chi_{b h}=\chi_{0}+\left(R_{a} F\right) / t_{c}=\left(R_{a} F\right) / t_{c}
$$

Where the air concentration, $\chi_{0}$, is approximately zero at some height far enough from the surface. The resistance to HTO transport $\left(R_{a}\right)$ in the atmosphere between the reference height, $z_{r}$ (where $C_{2}$ is very small) and the breathing height $\left(\mathrm{r}_{\mathrm{bhh}}\right)$ can be approximated from meteorological theory as

$$
\mathrm{R}_{\mathrm{a}}=\left(\ln \left(\mathrm{z}_{\mathrm{r}} / \mathrm{r}_{\mathrm{bh}}\right)\right)^{2} / \mathrm{u}
$$

and is dependent on the wind speed at the reference height $(u)$. The integrated exposure $\left(E_{x}\right)$ is found to be

$$
\begin{aligned}
E_{x} & =\chi_{b h} t_{c} \\
& =\left(R_{a} F t_{c}\right) / t_{c} \\
& =R_{a} v_{d} \chi_{a} t
\end{aligned}
$$

As indicated above the exposure time to HTO and mean concentration are not in the final expression which indicates expc iure is related to deposition and the mixing of HTO as it is re-emitted into the atmosphere. 
Given exposure, the methods proposed in ICRP $30{ }^{13}$ can be used to calculate the inhalation dose for the HT and the re-emitted HTO from the release. The inhalation dose due to both HT and re-emitted HTO can also be compared to the inhalation dose that would be calculated if the release had been entirely HTO.

Figure 1 shows that the ratio of dose from re-emitted HTO to dose from HT can be greater than 50 if the wind speed, and resulting atmospheric mixing are low. At higher wind speeds the ratio approaches unity as the HTO is mixed with air from outside the exposure area.

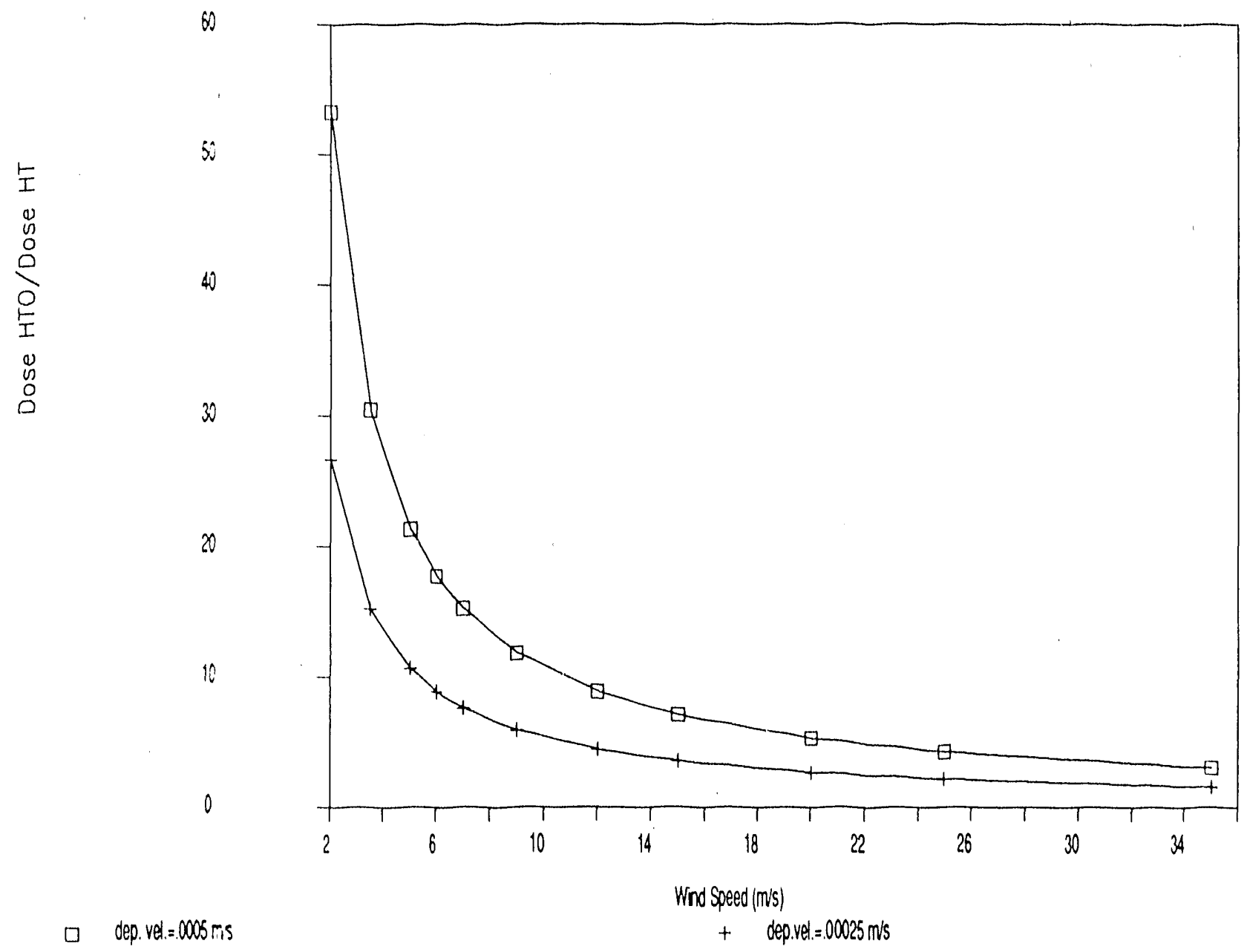

Figure 1. The Ratio of Inhalation Dose from Re-emitted HTO to Dose from HT. 
Figure 2 compares the inhalation dose from an HT release, including both inhalation of $\mathrm{HT}$ and inhalation of HTO, to the dose if all of the tritium had been in the form of HTO. The results are influenced by the deposition velocity of HT and the wind speed. The highest ratios for the range of wind speeds and deposition velocities explored are in the range of $0.2 \%$.

\section{Dose from $\mathrm{HT}$}

Equivalent HTO Dose

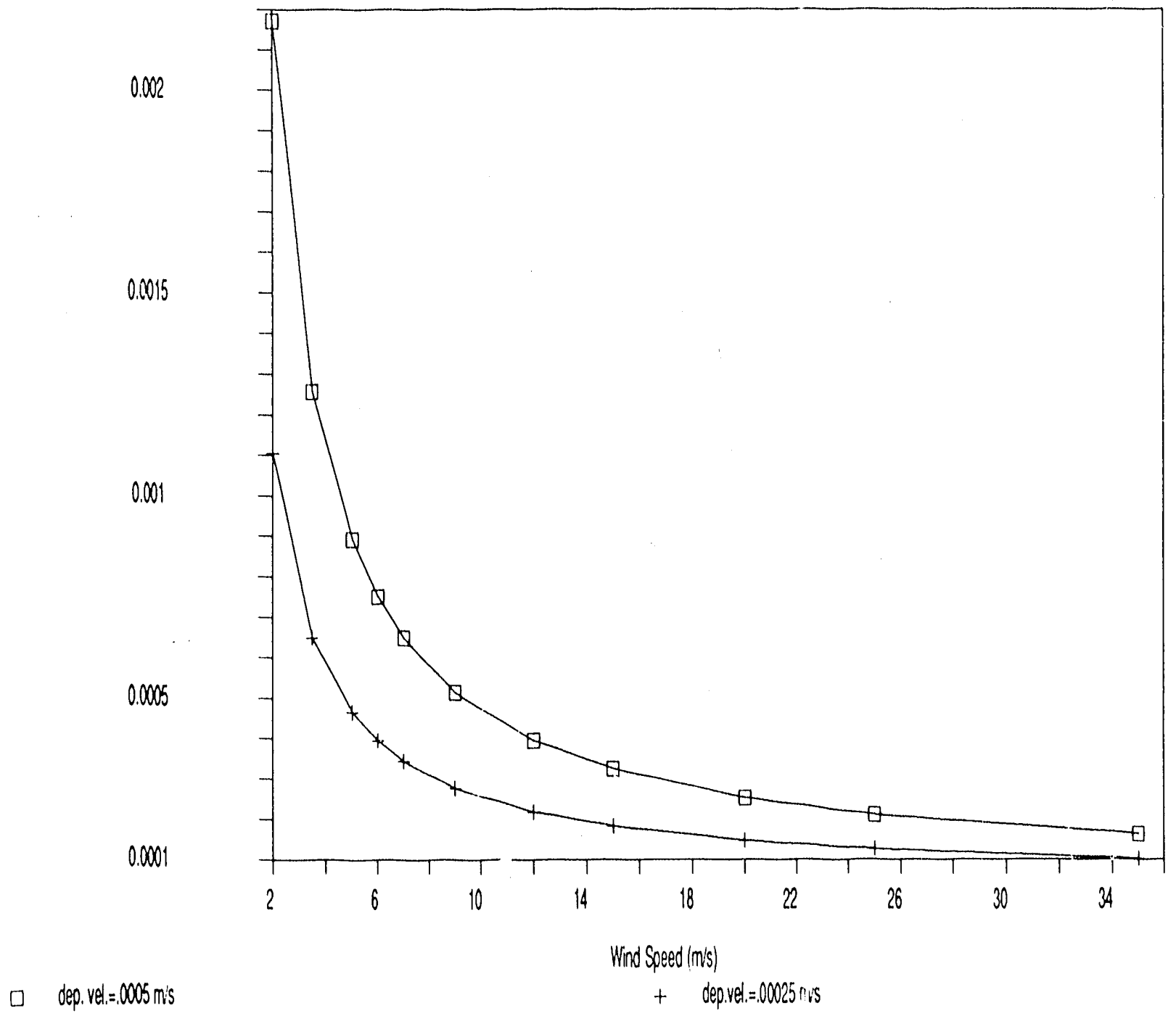

Figure 2. Comparison of the Inhalation Dose from an HT Release to the Dose from an HTO Release of the same Size. 
A sampling of the results of the calculations are given in Table 2 for an air concentration of $100 \mathrm{~Bq} / \mathrm{cu} . \mathrm{m}$. and an exposure period of 5 minutes.

This model assumes that the re-emitted HTO will, on the average, affect only the atmosphere directly above the site of deposition. This is certainly not the case. The HTO can be transported from the deposition site to another area which was not exposed to HT. In this case the ratio in Figure 1. would tend to infinity for this location, since the dose from HT is zero while there is some dose from the HTO transported from another site that was exposed to HTO. The transport of re-emitted HTO to site of low HT exposure may explain the high ratio measured in the experiment of Djerassi and Lesigne.

Table 2. Results of Calculations of the Dose due to Conversion of HT to HTO from an Atmospheric Release of HT.

\begin{tabular}{|c|c|c|c|}
\hline Inputs & & & \\
\hline $\begin{array}{l}\text { Air } \\
\text { Concentration }\end{array}$ & Exposure & Reference & Displacemen \\
\hline $\mathrm{Ba} / \mathrm{cu} . \mathrm{m}$ & $\mathbf{s}$ & m & $\mathbf{m}$ \\
\hline 100 & 300 & 30 & 1.5 \\
\hline
\end{tabular}

Results

\begin{tabular}{|c|c|c|c|c|c|c|}
\hline $\begin{array}{r}\text { Wind Exposure } \\
\text { Speed HT->HT( } \\
\mathrm{m} / \mathrm{s} \quad \mathrm{Ba}-\mathrm{s} / \mathrm{cu} \mathrm{m}\end{array}$ & $\begin{array}{r}\text { Exposure } \\
\text { HT } \\
\text { Ba-s/cum }\end{array}$ & $\begin{array}{r}\text { Dose } \\
\text { HT->HTO } \\
\text { SY }\end{array}$ & $\begin{array}{r}\text { Dose } \\
\text { HT } \\
\text { Sy }\end{array}$ & $\begin{array}{r}\text { Ratio } \\
\text { HT }>\text { HTO/ } \\
\text { HT }\end{array}$ & $\begin{array}{r}\text { Dose } \\
\text { If HTO } \\
\text { Sy }\end{array}$ & $\begin{array}{l}\text { Ratio } \\
\text { HT->HTO/ } \\
\text { If HTO }\end{array}$ \\
\hline
\end{tabular}

Deposition Velocity $=.00005 \mathrm{~s} / \mathrm{m}$

\begin{tabular}{|c|c|c|c|c|c|c|c|}
\hline & & & & & & & \\
\hline 2.0 & 63.9 & 30000 & $5.55 \mathrm{E}-13$ & $1.04 \mathrm{E}-14$ & 53.3 & $2.60 \mathrm{E}-10$ & 0.002131 \\
\hline 3.5 & 36.5 & 30000 & $3.17 \mathrm{E}-13$ & $1.04 \mathrm{E}-14$ & 30.4 & $2.60 \mathrm{E}-10$ & 0.001218 \\
\hline 5.0 & 25.6 & 30000 & $2.22 \mathrm{E}-13$ & $1.04 \mathrm{E}-14$ & 21.3 & $2.60 \mathrm{E}-10$ & 0.000853 \\
\hline 6.0 & 21.3 & 30000 & $1.85 \mathrm{E}-13$ & $1.04 \mathrm{E}-14$ & 17.8 & $2.60 \mathrm{E}-10$ & 0.000710 \\
\hline 7.0 & 18.3 & 30000 & $1.58 \mathrm{E}-13$ & $1.04 \mathrm{E}-14$ & 15.2 & $2.60 \mathrm{E}-10$ & 0.000609 \\
\hline 9.0 & 14.2 & 30000 & $1.23 \mathrm{E}-13$ & $1.04 \mathrm{E}-14$ & 11.8 & $2.60 \mathrm{E}-10$ & 0.000474 \\
\hline 12.0 & 10.7 & $3000)$ & $9.25 \mathrm{E}-14$ & $1.04 E-14$ & 8.9 & $2.60 \mathrm{E}-10$ & 0.000355 \\
\hline 15.0 & 8.5 & 30000 & 7.40 E-14 & $1.04 \mathrm{E}-14$ & 7.1 & $2.60 \mathrm{E}-10$ & 0.000284 \\
\hline 20.0 & 6.4 & 30000 & $5.55 \mathrm{E}-14$ & $1.04 \mathrm{E}-14$ & 5.3 & $2.60 \mathrm{E}-10$ & 0.000213 \\
\hline 25.0 & 5.1 & 30000 & $4.44 \mathrm{E}-14$ & $1.04 \mathrm{E}-14$ & 4.3 & $2.60 \mathrm{E}-10$ & 0.000171 \\
\hline 35.0 & 3.7 & 30000 & $3.17 \mathrm{E}-14$ & $1.04 \mathrm{E}-14$ & 3.0 & $2.60 \mathrm{E}-10$ & 0.000122 \\
\hline ion Ve & $=.00$ & $\mathrm{~s} / \mathrm{m}$ & & & & & \\
\hline 2.0 & 32.0 & 30000 & $2.77 \mathrm{E}-13$ & $1.04 \mathrm{E}-14$ & 26.6 & $2.60 \mathrm{E}-10$ & 0.001066 \\
\hline 3.5 & 18.3 & 30000 & $1.58 \mathrm{E}-13$ & $1.04 \mathrm{E}-14$ & 15.2 & $2.60 \mathrm{E}-10$ & 0.000609 \\
\hline 5.0 & 12.8 & $30000)$ & $1.11 \mathrm{E}-13$ & $1.04 \mathrm{E}-14$ & 10.7 & $2.60 \mathrm{E}-10$ & 0.000426 \\
\hline 6.0 & 10.7 & 30000 & $9.25 \mathrm{E}-14$ & $1.04 \mathrm{E}-14$ & 8.9 & $2.60) \mathrm{E}-10$ & 0.000355 \\
\hline 7.0 & 9.1 & 30000 & $7.92 \mathrm{E}-14$ & $1.04 \mathrm{E}-14$ & 7.6 & $2.60 \mathrm{E}-10$ & 0.000304 \\
\hline 9.0 & 7.1 & 30000 & $6.16 \mathrm{E}-14$ & $1.04 \mathrm{E}-14$ & 5.9 & $2.60 \mathrm{E}-10$ & 0.000237 \\
\hline 12.0 & 5.3 & 30000 & $4.62 \mathrm{E}-14$ & $1.04 \mathrm{E}-14$ & 4.4 & $2.60 \mathrm{E}-10$ & 0.000178 \\
\hline 15.0 & 4.3 & 30000 & $3.70 \mathrm{E}-14$ & $1.04 \mathrm{E}-14$ & 3.6 & $2.60 \mathrm{E}-10$ & 0.000142 \\
\hline 20.0 & 3.2 & 30000 & $2.77 \mathrm{E}-14$ & $1.04 \mathrm{E}-14$ & 2.7 & $2.60 \mathrm{E}-10$ & 0.000107 \\
\hline 25.0 & 2.6 & 30000 & $2.22 \mathrm{E}-14$ & $1.04 \mathrm{E}-14$ & 2.1 & $2.60 \mathrm{E}-10$ & 0.000085 \\
\hline 35.0 & 1.8 & 30000 & $1.58 \mathrm{E}-14$ & $1.04 \mathrm{E}-14$ & 1.5 & $2.60 \mathrm{E} \cdot 10$ & 0.000061 \\
\hline
\end{tabular}




\section{Calculation of HT Dose Under Worst Conditions}

In the previous calculations, the idea was developed that most of the tritium gas (HT) oxidized in the soil will reenter the atmosphere. In this case, the rate of reentry of deposited HT as HTO does not have a large effect on the dose. The factors which become important are the deposition rate and the climatology of the site where the release occurred. A worst case scenario at any distance from the release point would result from exposure to the center of the initial plume followed by being in the center of the reemmited HTO from the upwind deposition of HT. This would require a constant wind direction during the entire exposure period. The strategy that was developed to simulate this scenario has the following characteristics:

1. First calculate the ground-level concentration of HT at fixed intervals up to the distance of interest.

2. From the ground-level concentrations calculate the deposition between the source and the distance of interest.

3. Use the total deposition as a source term for HTO to calculate the concentration of HTO at the distance of interest.

The following calculations were made to determine the kind of response that can be expected under these environmental conditions. A simple, worst case meteorology would be a fumigation scenario. In this case, an atmospheric inversion would keep the plume from rising much above the release height and mixing underneath the inversion would be vigorous enough to mix the released HT throughout the layer of air. Under this scenario an average concentration of HT $(\chi)$ in the air layer can be calculated as:

$$
\chi=Q /\left(3 u L \sigma_{y}\right)
$$

Three times the standard deviation of the plume width $\left(\sigma_{y}\right)$ is used to include better then $99 \%$ of the gas. The wind speed $(u)$ and height of the mixed layer under the inversion $(\mathrm{L})$ complete the definition of the volume of air which includes the gas which is release at rate, $Q$. The standard deviation of the plume width will increase with distance from the source.

From equation (1) the rate of deposition at a given distance from the source can be calculated as the product of the deposition velocity $\left(v_{d}\right)$, the time of exposure $(t)$ and the area of soil exposed at that distance.

$$
D_{p}=v_{d} \chi t \sigma_{y}
$$

If the deposition rate is small enough that the deposition does not significantly deplete the amount of HT in the plume, equation (5) can be substituted in equation (6) to give the deposition rate at any distance from the source.

$$
D_{p}=\left(v_{d} Q t \sigma_{y}\right) /\left(u L s_{y}\right)=\left(v_{d} Q t\right) /(u L)
$$


Notice that the standard deviation of the plume width cancels. If the plume is wide the concentration is diluted but the area for deposition is large. The converse is true if the plume width is small. This also means that the deposition rate will remain the same at all distances from the source, as the plume increases in width with the distance from the source, the concentration will decrease with dilution but the area for deposition will increase. In this case the total deposition between the source and some distance of interest is simply the product of the deposition rate and the distance $\left(D_{T}=D_{p} d\right)$.

A strategy that can be used when the amount of HT in the air is depleted by deposition is the source depletion calculation. In this scheme, the release rate $(\mathrm{Q})$ is decreased enough in the calculation at each distance to account for the HT lost by deposition between the source and that distance. For the simple conditions postulated in these calculations the depletion of the source will lead to an exponential decrease with distance and the total deposition between the source and the distance of interest will equal the source depletion in that distance or

$$
D_{r}=Q_{i}-Q_{i n}=Q_{i}\left[1-\exp \left(\left(-v_{d} / u L\right) x\right]\right.
$$

The total deposition can be used in a Gaussian plume model to calculate the centerline air concentration under fumigation conditions

$$
\chi=D_{\cdot J} /\left(\left(2 \sigma_{y}\right)^{-1 / 2} \mathrm{u} \mathrm{L}\right)
$$

Dose can be calculated from exposure (pioduct of the concentration and the exposure time) and the dose factor for HTO.

The results of these calculations are given in Table 3 and illustrated in figures 3 and 4 . Figure 1 indicates the ratio of dose from converted HTO to dose from HT. The ratios are quite high, on the order of 1000 at $10 \mathrm{~km}$ in the $.001 \mathrm{~m} / \mathrm{s}$ deposition velocity case. The ratio is still in the order of 100 for lower (more likely) deposition velocities. The dose calculated from the data of Djerassi and Lesigne ${ }^{2}$ is shown to provide a comparison. This data should not be used to justify the lower deposition velocity since they were collected during a period when the mixed layer was higher than the $100 \mathrm{~m}$ used in the calculations. The deeper mixed layer will lead to more dilution and less deposition at the same deposition velocity. This suggests that the deposition velocity was higher than 0.00025 . Measurements during the release indicate deposition velocities in the range of $.0001 \mathrm{~m} / \mathrm{s}$ for pasture and bare field to $.001 \mathrm{~m} / \mathrm{s}$ for forests.

Figure 4 shows the ratio of dose from the HT release, including HT and HTO dose, and the dose expected if the release had been all HTO. The input parameters are for a postulated worst case with high HT deposition $(.001 \mathrm{~m} / \mathrm{s})$, shallow mixed layer $(100 \mathrm{~m})$, low wind speed $(2 \mathrm{~m} / \mathrm{s})$, and moderately high mixing within the mixed layer (neutral atmospheric mixing below the inversion). The results predict that the ratio of dose from HTO to dose from HT in the release will increase with distance from the source. As a result of this increase the ratio of total dose from an HT release to a similar HTO release will also rise with distance from the source. The calculations suggest that at $10 \mathrm{~km}$ from the source the dose from conversion of HT to HTO in the soil during an HT release can be as much as $5 \%$ of the dose from an HTO release of similar size under the extreme conditions used for these calculations. 


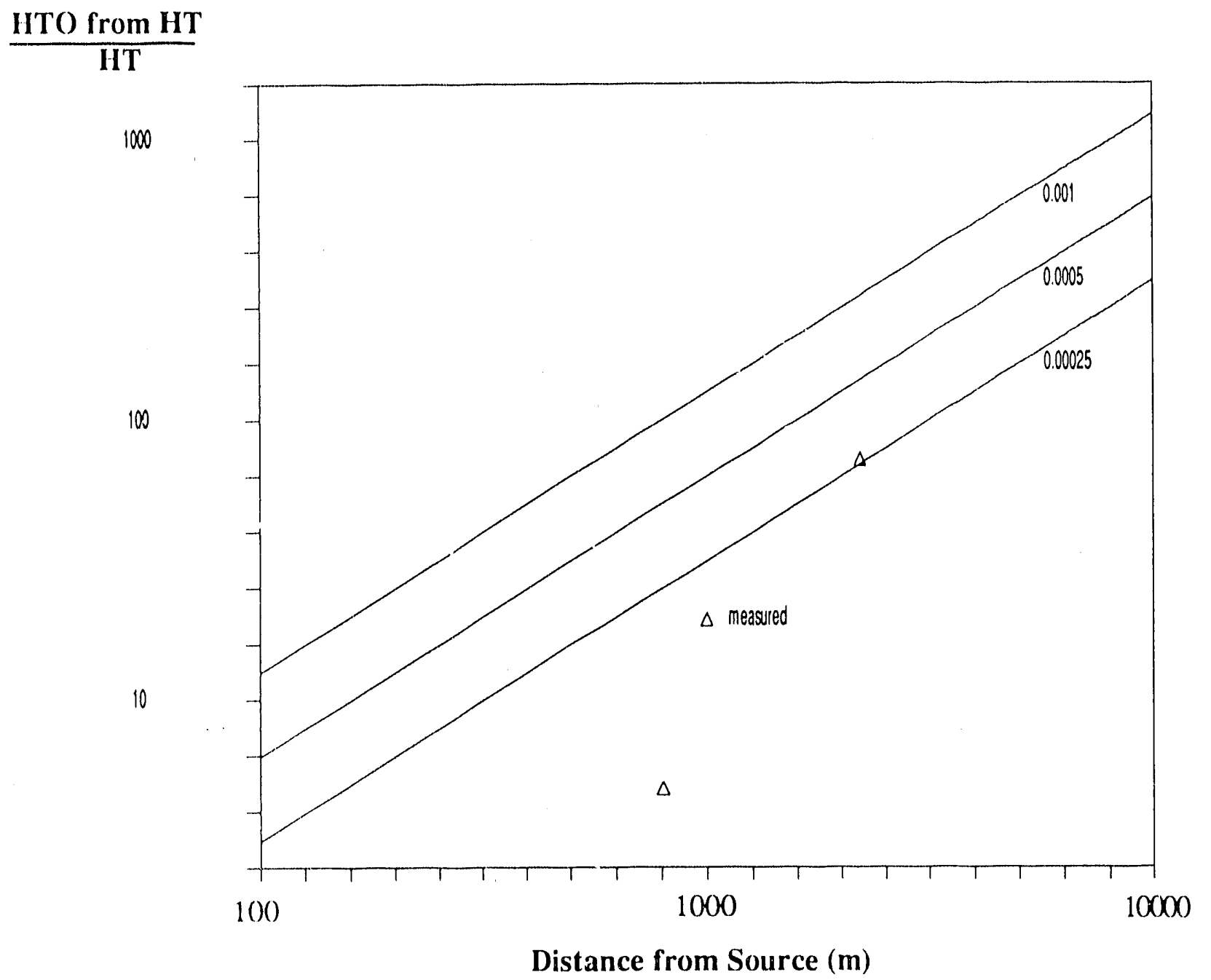

Figure 3. Comparison of Dose from Conversion of HT to HTO and HT Inhalation only. 
HTO (after HT)

HTO (after HTO)

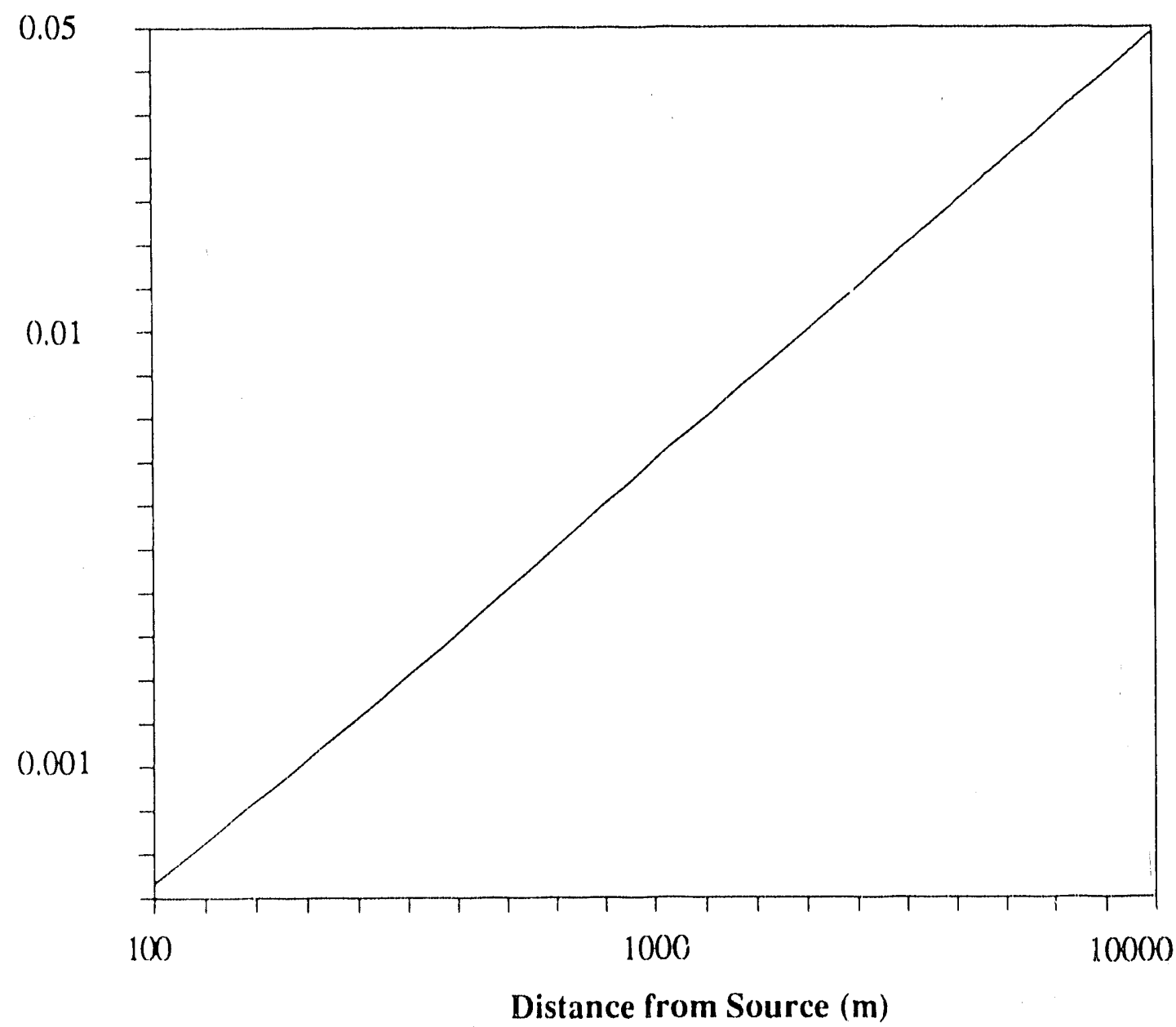

Figure 4. Comparison of the Doses from an HT Release, including HT Oxidation to HTO in Soil, and the Dose from an HTO Release of the same Size. 
Table 3. Calculation of Effect of HT to HT() Conversion by Soil for Fumigation Conditions at Mixing Depth of 100 Meters, Deposition Velocity of $0.001 \mathrm{~m} / \mathrm{s}$, Wind Speed of $2 \mathrm{~m} / \mathrm{s}$. Release Time of 60 Minutes, and a $100 \mathrm{~Bq} / \mathrm{s}$ Release Rate.

\begin{tabular}{|c|c|c|c|c|c|c|c|c|c|}
\hline dist & Q & $d p$ & $\mathrm{HT}->\mathrm{HTO}$ & If HTO & HT'> HTO & If HTO & HT & \multicolumn{2}{|c|}{ HTO/HT->HTO } \\
\hline (m) & $\mathrm{Ba} / \mathrm{s}$ & $\mathrm{Ba}$ & Ba/cum & Ba/cum & $\underline{S y}$ & $\underline{S y}$ & $\underline{S y}$ & $\mathrm{HT}$ & If IITO \\
\hline 500 & 99.75 & 899 & $1.27 \mathrm{E}-05$ & $5.11 \mathrm{E}-03$ & $3.98 \mathrm{E}-\overline{16}$ & $1.59 \mathrm{E}-13$ & $6.38 \mathrm{E}-18$ & 62 & 0.0025 \\
\hline 1000 & 99.50 & 1796 & $1.30 \mathrm{E}-(05$ & $2.61 \mathrm{E}-03$ & $4.07 \mathrm{E}-16$ & $8.17 E-14$ & $3.26 \mathrm{E}-18$ & 125 & $0.0(050$ \\
\hline 1500 & 99.25 & 2690 & $1.33 \mathrm{E}-(05$ & $1.78 \mathrm{E}-03$ & $4.16 \mathrm{E}-16$ & $5.57 E-14$ & $2.22 \mathrm{E}-18$ & 187 & 0.0075 \\
\hline $200(0)$ & 99.00 & 3582 & $1.35 E-05$ & $1.36 \mathrm{E}-03$ & $4.24 \mathrm{E}-16$ & $4.26 \mathrm{E}-14$ & $1.7(0) \mathrm{E}-18$ & 249 & 0.0100 \\
\hline 2500 & 98.76 & 4472 & $1.38 \mathrm{E}-05$ & $1.11 \mathrm{E}-0.3$ & $4.32 \mathrm{E}-16$ & $3.48 \mathrm{E}-14$ & $1.39 \mathrm{E}-18$ & 311 & 0.0125 \\
\hline 3000 & 98.51 & 5360 & $1.41 E-05$ & $9.47 \mathrm{E}-() 4$ & $4.40 \mathrm{E}-16$ & $2.96 \mathrm{E}-14$ & $1.18 \mathrm{E}-18$ & 372 & 0.0149 \\
\hline 3500 & 98.27 & 6245 & $1.43 E-05$ & $8.27 E-() 4$ & $4.48 \mathrm{E}-16$ & $2.58 \mathrm{E}-14$ & 1.03E-18 & 434 & 0.0174 \\
\hline 4000 & 98.02 & 7128 & $1.46 \mathrm{E}-05$ & $7.37 \mathrm{E}-(04$ & $4.56 \mathrm{E}-16$ & $2.30 \mathrm{E}-14$ & $9.21 \mathrm{E} \cdot 19$ & 495 & 0.0198 \\
\hline 4500 & 97.78 & 8010 & $1.48 \mathrm{E}-(05$ & $6.67 \mathrm{E}-() 4$ & $4.63 \mathrm{E}-16$ & $2.08 \mathrm{E}-14$ & $8.34 \mathrm{E}-19$ & 556 & 0.0223 \\
\hline 5000 & 97.53 & 8888 & $1.50 \mathrm{E}-(05$ & $6.10 \mathrm{E}-04$ & $4.71 \mathrm{E}-16$ & $1.90 \mathrm{E}-14$ & $7.63 \mathrm{E}-19$ & 617 & 0.0247 \\
\hline 5500 & 97.29 & 9765 & $1.53 \mathrm{E}-05$ & $5.64 \mathrm{E}-0.4$ & $4.78 \mathrm{E}-16$ & $1.76 \mathrm{E}-14$ & 7.05E-19 & 678 & 0.0272 \\
\hline 6000 & 97.04 & 10640 & $1.55 \mathrm{E}-() 5$ & $5.25 \mathrm{E}-04$ & $4.85 \mathrm{E}-16$ & $1.64 \mathrm{E}-14$ & $6.57 \mathrm{E}-19$ & 739 & 0.0296 \\
\hline $65(0)$ & 95.80 & 11512 & $1.57 \mathrm{E}-05$ & 4.92E-()4 & $4.92 \mathrm{E}-16$ & $1.54 \mathrm{E}-14$ & $6.15 \mathrm{E}-19$ & 799 & 0.0320 \\
\hline $70(0)$ & 96.56 & 12382 & $1.59 \mathrm{E}-05$ & $4.64 \mathrm{E}-(04$ & E-16 & $1.45 \mathrm{E}-14$ & 5.8() $\mathrm{E}-19$ & 860 & 0.0344 \\
\hline 75() 0 & 96.32 & 13250 & 1.6 & $4.39 \mathrm{E}-04$ & -16 & $1.37 \mathrm{E}-14$ & $5.49 \mathrm{E}-19$ & 920 & 0.0368 \\
\hline 8000 & 96.08 & 14116 & 1.6 & $4.18 \mathrm{E}-(04$ & E-16 & $1.30 \mathrm{E}-14$ & $5.22 \mathrm{E}-19$ & 980 & 0.0393 \\
\hline 8500 & 95.84 & 14979 & $1.66 \mathrm{E}-05$ & $3.99 \mathrm{E}-(04$ & $5.185-16$ & $1.24 \mathrm{E}-14$ & $4.98 \mathrm{E}-19$ & $1(1) 40$ & 0.0416 \\
\hline 9000 & 95.60 & 1.5841 & $1.68 \mathrm{E}-(05$ & $3.81 \mathrm{E}-() 4$ & $5.25 \mathrm{E}-16$ & $1.19 \mathrm{E}-14$ & $4.77 \mathrm{E}-19$ & 1100 & 0.0440 \\
\hline 9500 & 95.36 & 167()() & $1.70 \mathrm{E}-05$ & $3.66 \mathrm{E}-04$ & $5.31 \mathrm{E}-16$ & $1.14 \mathrm{E}-14$ & $4.58 \mathrm{E}-19$ & 1160 & 0.0464 \\
\hline 0000 & 95.12 & 17557 & $1.72 E-05$ & $3.52 \mathrm{E}-04$ & $5.37 \mathrm{E}-16$ & $1.10 \mathrm{E}-14$ & $4.40 E-19$ & 12.19 & 0.0484 \\
\hline
\end{tabular}

\section{Estimation of Deposition Velocities from Atmospheric HT Half-Life}

Mason and Ostlund (1979) have estimated that the net lifetime of HT in the atmosphere is between 5 and 6 years. On this time scale, as opposed to the previous calculations, radioactive decay must also be considered. The disappearance of $\mathrm{HT}$ from the atmosphere can be estimate from the chemical conversion $\left(\lambda_{\mathrm{c}}\right)$ and radiation decay $\left(\lambda_{\mathrm{r}}\right)$ factors

$$
Q=Q_{i} \exp \left[\left(-\lambda_{c}+\lambda_{r}\right)\right] t=Q_{i} \exp \left(\left(-v_{d} / L_{1}\right)+\lambda_{r} t\right)
$$

This is analogous to equation (8) and from this analogy the chemical decay constant is equal to the deposition velocity divided by the mixed depth of the atmosphere. The radioactive decay constant,$\lambda_{r}$, is 0.0565 (assuming all tritium is HT). Table 4 shows the influence of mixing depth and deposition velocity on the time needed to remove $50 \%$ and $95 \%$ of the HT from the atmosphere. The mixing depth of 12 and $15 \mathrm{~km}$ were picked because they have been shown to be in good agreement with the half residence time and deposition velocities calculated for $\mathrm{HTO}^{14}$. The results of these calculations are in reasonable agreement with the 4.8 year tritium atmospheric life time determined by Mason and Ostlund ${ }^{15}$ from atmospheric HT measurements. 
Table 4. The Effect of Mixed Depth and Deposition Velocity on the Long-Term Removal of Tritium HT from the Atmosphere.

\begin{tabular}{|c|c|c|c|c|c|}
\hline $\begin{array}{l}\text { Mixed } \\
\text { Depth }\end{array}$ & $\begin{array}{l}\text { Deposit. } \\
\text { velocity }\end{array}$ & \multicolumn{2}{|c|}{$\begin{array}{l}\text { Time to } \\
\text { Remove } 50 \%\end{array}$} & \multicolumn{2}{|c|}{$\begin{array}{l}\text { Time to } \\
\text { Remove } 95 \%\end{array}$} \\
\hline (m) & $(\mathrm{m} / \mathrm{s})$ & years & diuss & years & days \\
\hline 10() & 0.00100 & $\overline{0.002}$ & 0.8 & 0.009 & 3.5 \\
\hline 10000 & 0.00100 & 0.220 & 80.2 & 0.950 & 346.7 \\
\hline 15000 & $(0.00100$ & 0.330 & 120.3 & 1.425 & 520.1 \\
\hline 100 & $(0.0) 025$ & 0.009 & 3.2 & 0.038 & 13.9 \\
\hline 12000$)$ & $0.00(0) 25$ & 1.055 & 385.1 & 4.560 & 1664.3 \\
\hline 15000 & $(0.000) 25$ & 1.319 & 481.4 & 5.700 & $208(0.4$ \\
\hline
\end{tabular}

\section{CONCLUSIONS}

From the preceding analysis it is evident that the ratio of dose from inhalation of tritium following an atmospheric release of HT, as compared to inhalation of HTO, is closer to 0.01 than to the $(0.0001$ attributed to simple HT inhalation. The source of the additional dose is from the oxidation of HT to HTO in the environment. The location of oxidation is in the soil and is mediated by soil microorganisms.

Under meteorologic conditions which keep the HT release near the surface and promote optimum soil microbial activity, the analysis suggests that the ratio of dose from an atmospheric HT release could be as high as $5 \%$ of that from an atmospheric HTO release.

\section{SUMMARY}

Measurements of uptake of tritium by humans and laboratory animals following exposure to tritiated hydrogen gas, HT, suggest that the radiotoxicity of HT is four orders of magnitude less than that of tritiated water, HTO. However, this analysis does not take into account the conversion of HT into HTO following release into the environment. Experimental releases of HT have demonstrated that the majority of dose from an HT release was the result of HTO converted before release or by soil microorganisms in the environment after the release.

In this report two methods are used to estimate the effect of HT to HTO conversion on the inhalation dose of individuals exposed to to tritium downwind of a release of HT. This analysis inciicates that the dose from inhalation of tritium following an atmospheric release of HT is closer to $1 \%$ of the dosa from an HTO release, rather than to the $0.01 \%$ attributed to simple HT inhalation. Under unfavorable conditions the HT dose could be as high as $5 \%$ of the dose of an HTO release. 


\section{REFERENCES}

1. Watts, J.R. and C.E. Murphy Jr. 1979. Comparison of calculated and measured radiation doses from chronic aqueous releases. Health Phys. 36(4): 519-521.

2. Djerassi, H. and B. Lesigne. 1988. Enviromental Tritium Behavior: Final Report. CEA, IPSN, Saclay, France.

3. Garland, J. A. and L. C. Cox. 1980. The absorption of tritium gas by English soils, and plants and the sea. Water, Air and Soil Pollution 14 103-114

4. Sweet, C. W. and C. E. Murphy Jr. 1981 Oxidation of molecular tritium by intact soils. Environmental Science \& Technology $15,1485-1487$

5. Dunstall, T. G., G. L. Ogram, F. S. Spencer. 1985. Elemental tritium deposition and conversion in the terrestrialenvironment. Fusion Technology 8(2):2551-2556.

6. Foerstel, H. 1988. HT and HTO conversion in the soil and subsequent tritium pathway: Field release data and laboratory experiments Fusion Technology 14(2):1241-1246.

7. Ogram, G. L., F. S. Spencer and R. M. Brown. 1988. Field studies of HT behavior in the environment: 2. The interaction with soil. Fusion Technology 14(2):1170-1175.

8. Taeschner, M., B. Wiener, C. Bunnenberg. 1988. HT dispersion and deposition in soil after experimental releases of tritiated hydrogen. Fusion Technology 14(2):1264-1272.

9. Brown, R.M., G.L. Ogram, and F.S. Spencer.1990. Oxidation and dispersion of HT in the environment: The August 1986 Field experiment at Chalk River. Health Physics 58: 171-181.

10. Feinhals, J. and C. Bunnenberg. 1988. Laboratory investigations of HTO deposition to soils. Fusion Technology 14(2):1253-1257.

11. Belot, Y., J. Guenot, C. Caput. 1988. Emission to atmosphere of tritiated water formed at soil surface by oxidation of HT. Fusion Technology 14(2):1231-1234.

12. Wiener, B., M. Taeschner and C. Bunnenberg. 1988. HTO reemission from soil after HT deposition and dose consequences of of HT releases. Fusion Technology 14(2):1247-1252.

13. ICRP. 1979. Limits for Intakes of Radionuclides by Workers, ICRP Publ. No. 30,Part 1. ICRP 4 $(1 / 2)$. 
14. NCRP. 1979. Tritim in the Environment. Nation Council on Radiation Protection and Measurement, Washington, DC

15. Mason, A. S. and H. G. Ostlund. 1979. Atmospheric HT and HTO: Distribution and large scale circulation. In: Behavior of Tritium in the Environment, pp 3-15, IAEA, Vienna. 

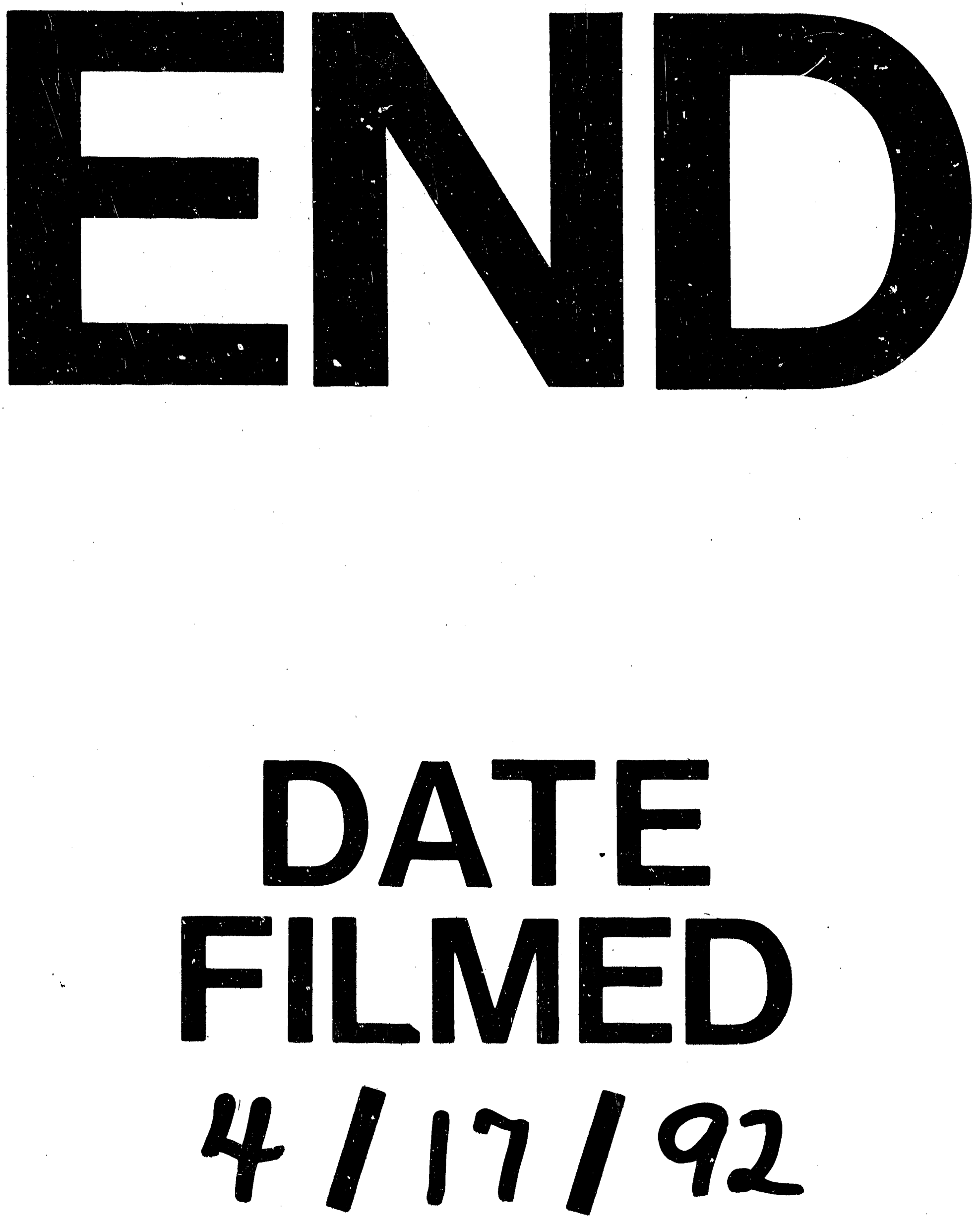
